David Brčić

E-mail: brcic@pfri.hr

Srđan Žuškin

E-mail: szuskin@pfri.hr

University of Rijeka, Faculty of Maritime Studies, Studentska 2, 51000 Rijeka, Croatia

\title{
Towards Paperless Vessels: A Master's Perspective
}

\begin{abstract}
The transitional period of implementation of the Electronic Chart Display and Information System (ECDIS) expired on July 1st, 2018. As for this date onward, vessels of 3000 GT or more subject to the Safety of Life at Sea (SOLAS) Convention and engaged in international voyages, must be fitted with an official ECDIS system. The Convention furthermore requires mandatory possession of navigational equipment as an adequate back-up. In case that independent system is used for this purpose, there is no further obligation for a vessel to possess traditional paper navigational charts and it can be considered as paperless. Beside paper charts, this term also implies digital nautical publications and probably an electronic ship's $\log$ in the foreseeable future. The interpretation of ECDIS differs considering particular rank of an Officer of the Watch (OOW) and its engagement towards the system. The system should be accepted by OOWs as true end-users. The proposed paper elaborates opinions and standpoints of decisive end-users towards the system, its role as a primary navigational means, and the fact that traditional navigation conduct is replaced by digital means. For this purpose a survey between OOWs was conducted focusing on their answers to respective questions. The sample size allowed for the observation of opinions over several years and the definition of the ECDIS acceptance level. Results are presented and discussed together with proposals of new activities which have to be carried out to improve the safety of navigation by the ECDIS system and its further development.
\end{abstract}

Key words: maritime navigation, electronic chart display and information system, officers of the navigational watch, maritime education and training, ECDIS EHO

\section{Introduction}

After the official acceptance of the ECDIS system as meeting the chart carriage requirements of the Safety of Life at Sea (SOLAS) Convention, the transitional period of the system implementation commenced on July $1^{\text {st }}, 2012$ for the following 6 years [28]. As safety improvement in conducting maritime navigation, the system represents a substantial step towards digital navigation and its perception. The current year marks 
the completion of this period, where possession of at least one official system on vessels engaged in international voyages is required.

During the mentioned period (and earlier), the system evolved from its first concept, integrating more elements with display and operational enhancements as well. So far, it represents a primary navigation means. In certain cases where an adequate back-up of the system is provided, the vessel can sail without its updated paper navigational charts (Appropriate Portfolio of Paper Charts - APC). In these terms, the vessel can be considered as paperless, referring not only to APC, but also on digital nautical publications, vessel's logs and software incorporated both in the ECDIS system or acting as standalone units.

The timeline of ECDIS implementation wasn't straightforward all of the time. Several issues were recognized during this process, which resulted in new standards, regulations and guidelines to ease the implementation process, simplification of ECDIS usage and handling and adaptation of Officers of the Watch (OOWs). At the present moment, certain problems still remain as potential threats for successful conducting and completion of the sailing venture. Beside technical issues, it especially refers to proper handling with the system, implying background knowledge and proper interpretation. The means of navigation and required knowledge still persist; however, the navigational tool is changing, which requires additional level of knowledge and understanding. It is a specific period where reduction in the usage of traditional navigational means and growing presence of digital ones can be noticed. Before any concrete education takes place, the OOW should get familiar with the sole idea / concept of the system. This is often misused.

Various OOW ranks perceive the system and new navigation differently, depending on their engagement, their experience as well as their role in the bridge team and their respective tasks. In this accordance, there should be a clear interpretation by true endusers regarding the system, eventual paper chart reduction or even withdrawal and transferring to digital navigational means. This was the motivation for the proposed research considering the interaction and perception of OOWs towards the system, the completion of mandatory implementation period and handling. The aim of the research was the definition of the level of ECDIS acceptance after the completion of the implementation period as seen by Masters, regarding their participation and involvement. The objectives can be stated as identification of opinions on sufficiency of the system replacement for traditional paper charts and comparison of these two means of navigation. The research is based on the survey conducted in the period 20142018 , covering the major portion of the ECDIS implementation period. The survey in general was originally distributed among all OOW ranks at the international level, including apprentice officers but also ECDIS stakeholders other than active seafarers. Results were summarized and discussed and main findings are herein presented. The study resulted in the emergence of new desirable activities and proposals representing the continuation of the research. 


\section{Background}

The ECDIS system has emerged as a hydrographic data exchange tool between national hydrographic offices in terms of chart production and updating $[1,10]$. Recognizing the potential of the new marine navigation system, the International Maritime Organization (IMO) took over the coordination and guidance on the system development. The idea was to integrate navigational data to the mariner, such as the true position, environmental conditions, radar image and chart information [10]. Together with the International Hydrographic Organization (IHO), IMO initiated standards for the industry, both the system-centered and chart-centered ones [1, 30, 9]. The first Performance Standards (PS) for ECDIS equipment were provided in 1995 [20]. With the passing of time, the development of the system and the gained experience, including the newly emerged issues, the PS was getting complemented by various amendments making reference not only to performance standards but also to back-up arrangements, good practice, new technologies and issues which emerged from the system's usage [21, 22]. In 2006, the revised edition of Performance Standards was adopted and has remained in force still today [23].

ECDIS is a navigation information system having the purpose to assist mariners in conducting the navigation, a process which implies a variety of tasks [23, 29]. It should provide navigational and any additional navigation-related information required for safe navigation. The main ECDIS tasks may be categorized as route planning and route monitoring, being the main components of the sailing venture carried out by the seafarer. One of the advantages of the system as compared to the paper chart navigation is its ability to trigger alarms, alerts and indications for a variety of navigational parameters, thus enabling a proper and timely reaction. The main features of the system are the integration of navigational equipment and fusion of navigational data. The architecture of a typical ECDIS system is presented in Figure 1.

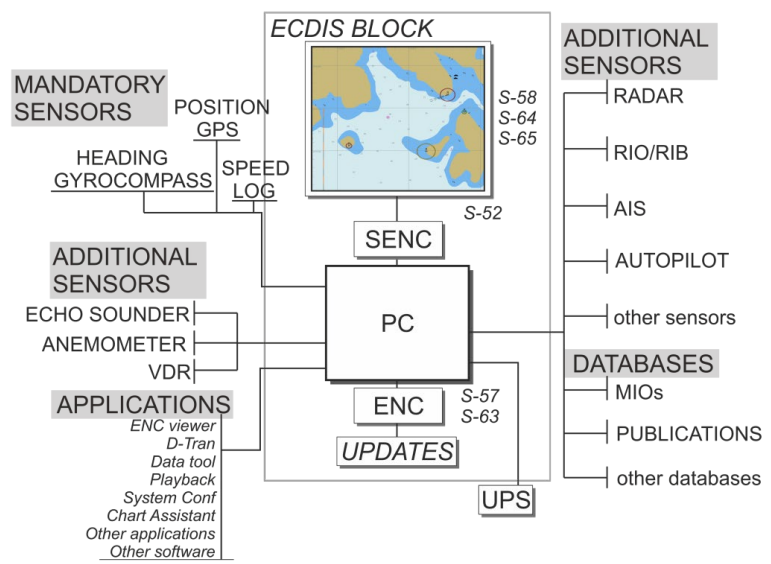

Figure 1 -ECDIS architecture. Based on the CTransas NaviSailor 4000 example 
If all requirements are satisfied, the system can be accepted as an adequate replacement for paper navigational charts [28, 20, 23, 17]. Requirements refer to IMO standards regarding the system's performance, IHO standards regarding technical specifications regarding electronic data (Electronic Navigational Charts - ENC), and standards related to equipment operational requirement and testing, regulated by the International Electrotechnical Commission (IEC). The system is accepted as meeting the carriage requirements [10], however the Convention requires an adequate back-up arrangement. According to [17], the following means are allowed for this purpose:

i. Paper charts,

ii. A second, independent compliant system with a separate power supply and separate positioning sensor, and

iii. A chart radar unit with a separate power supply.

There are several statuses to be found on board vessels, varying from APC as a back-up arrangement, to three or more ECDIS independent units fitted on navigational bridges. In case of ii) and iii), the vessel can be considered as paperless, without the obligation to carry paper charts, although certain flag state administrations and particular shipping companies do dictate an Emergency Set of Paper Charts (ESP). According to the United Kingdom Hydrographic Office [35], 51\% of all vessels subject to respective carriage requirements were ECDIS ready in 2015, which was in the middle of the implementation period. Although the Organizations dictate rigorous (systemcentered, chart-centered and educational) requirements for the system or electronic back-up arrangement, there is a growing trend in vessels without paper charts to rely on electronic means only. The ECDIS system represents a basis towards digital ships and the emergence of cloud-based technologies and e-Navigation [33].

During the period of system implementation, official reports and survey findings referring to ECDIS problems and handling issues [13, 25, 24, 27] resulted in edition and implementation of revised standards, which had to be satisfied for the system to be considered as approved [37]. From the technical aspect, the improved functionality reflects on the standardization of displays as well as of primary ECDIS functions, including standardized route file formats, symbols and abbreviations, standardized default control settings, system compliance with new polar requirements, improved alarm management and system integration with other equipment (e.g. BNWAS, BAM and VDR), etc. [11, 12]. Several IHO standards refer to revised technical specifications of ENCs' display (presentation library), to the ENC data protection scheme and new test data sets for the system $[14,15,16,18,19]$. IHO standards entered into force on August 31st, 2017 and IEC standards affect all vessels from August 19th, 2015.

The ECDIS Education and Training (EET) are straightforward to some extent. The Generic training is a basic, mandatory training, referring to navigation with the system in general [26]. The familiarization or a type specific training is required for the particular system that the OOW is to handle, be it the on-board handling or training prior to embarkation. The latter is being often conducted in the form of Computer Based 
Training (CBT). Entry standards for trainees attending the generic ECDIS course meaning also proper handling of the system in conducting navigation - are as follows: formal, basic knowledge in terrestrial navigation, familiarization and experience with visual navigation, accomplishment of supervised bridge watch keeping duties and possession of basic radar equipment certificate [26]. The last stated entry standard refers to considerable familiarization with computing operating systems, i.e. a certain level of informatics literacy. Beside the technical aspect, among all recognized issues in ECDIS handling, a significant share refers to problems regarding training and interpretation of the system in general. A number of ECDIS-related accidents support this fact, together with vessels' detentions and fines due to improper handling and lack of required level of knowledge [5].

\section{Previous research}

Notwithstanding the fact that the system contributes to safe navigation, there are several operational, functional and educational issues still persisting, which were recognized during the implementation period [36]. Among all stakeholders, OOWs are central ECDIS end-users. Considering system problems, issues are often intertwined (Figure 2), potentially leading to near misses and marine accidents $[3,39,31,6,7,8$, 34]. Growing emergence of additional system features are drawing attention away from basic functions and the system's initial purpose.

There have been several studies conducted on the ECDIS Education and Training (EET). Considering the age of seafarers in relation to the acceptance of the system, it is a common opinion that elder OOWs accept the system as a new, computing technology harder than their younger colleagues. In 2017, considerable share of respondents stated that 40 hours of ECDIS generic training is insufficient [4]. It has been proven and discussed in [32] that seafarers with little or no experience with the system familiarization gain more learning potential than the experienced users. The authors discuss the commonly accepted assumption that younger OOWs handle the system better due to their information literacy [32], indicating that the age and the experience of a particular user are not necessarily crucial factors for proper understanding and system handling. Subtly, the system can be considered as the situation awareness rising means, but also as a cause of over-reliance. Figure 2 shows the categorization of problems with ECDIS handling [3]. 


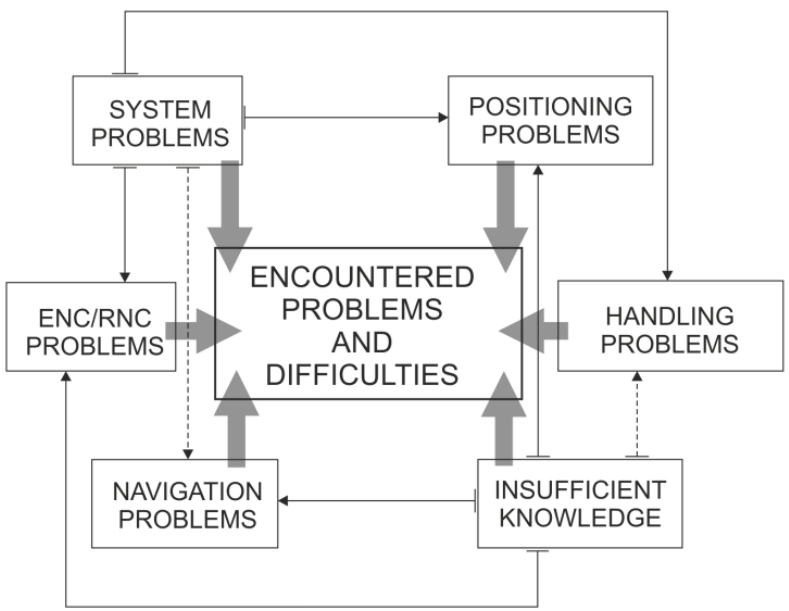

Figure 2 - Recognized problems in ECDIS handling as seen by OOWs [3]

Apart from training issues, certain misinterpretation between OOWs was found regarding basic safety settings and primal system features $[2,38]$, recalling insufficient level of knowledge. Possible future reduction of paper charts and transferring to digital navigation means were the motivation for the conducted study. Opinions from Masters are considered as relevant in the navigation venture conduct. The respective survey and the methodology are presented in the following section.

\section{The survey and the methodology}

The ECDIS EHO (Experience, Handling and Opinion) research commenced at the beginning of the implementation period. It aims at the educational process improvement and development of effective educational framework directed towards current, as well as future officers of the navigational watch. Among various educational, practical and research activities it focuses on the development of a proper feedback from OOWs as true end-users of the system. One of research tools is the international questionnaire, consisting of basic and operational questions regarding system handling. The results presented in this paper refer to opinions on the paper chart replacement and usage of the ECDIS system as the primary (and possibly the only) navigational means. The proposed research is focused on Masters and their standpoints as decisive and responsible OOWs. One of the objectives focused on their opinion about the system and its mandatory implementation although they were not necessarily directly involved in system handling. It refers especially to opinions of Masters who have never had the opportunity to work with the system. As for the general classification, the aim was to find proper guidelines and suggestions which should ease the communication between ranks forming a bridge team. 
The following introductory questions were used to categorize the profile of respondents:

- Rank,

- Working experience,

- ECDIS experience,

- Type of ECDIS education.

The survey contains answers from 353 respondents: 99 Masters (M), 77 Chief Officers (1/O), $672^{\text {nd }}$ Officers (2/O), $133^{\text {rd }}$ Officers (3/O), 2 Superintendents (SI), 2 Supervisors (SV), 3 Safety Officers, 1 Marine Safety Consultant (MSC), 8 Staff Captains (SC), 3 Environmental Officers (EO), 4 Dynamic Positioning Officers (DPO), 17 Port State Control Officers (PSCO), 1 Pilot (P) and 31 Undefined respondents (U). Among all respondents who fulfilled the questionnaire, 312 (88\%) are active seafarers ranging from apprentice officers to Masters (Figure 3). Although unknown, undefined respondents form part of the bridge navigational watch team.
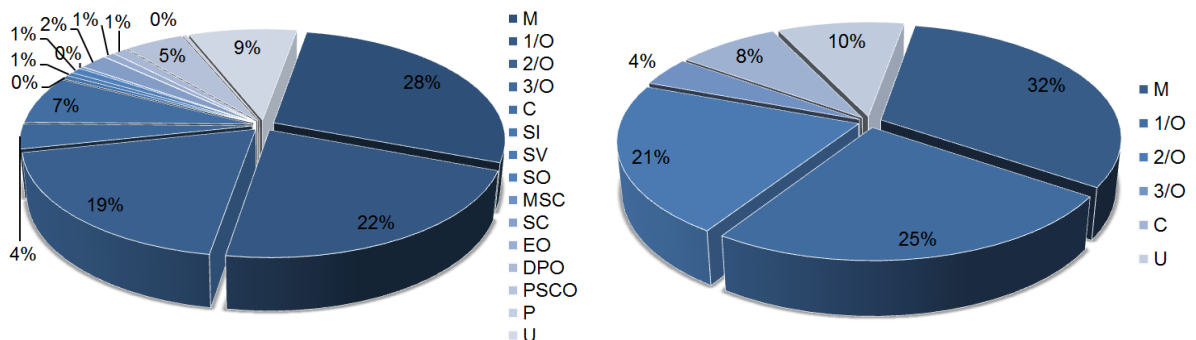

Figure 3 - All (left) and OOW (right) ECDIS EHO respondents

Answers of 99 respondents were further elaborated, presenting the target group of the study. After the analyses of answers and their share, as well as the definition of groups according to various criteria, the following questions and respective answers were used:

- Do you agree with the fact of withdrawal of the paper charts from the service, if certain conditions are met regarding ECDIS system, i.e. there is no further obligation to possess the same? (Q1)

- Do you think that there are still advantages of paper charts and traditional navigation means over ECDIS/ENC? (Q2)

This allowed that beside their answers, respondents' comments can also be considered. The comments refer to all of the 99 Master respondents, notwithstanding their experience with the system and seagoing experience. Figure 4 presents the distribution of Masters' category of respondents by their seagoing experience. 


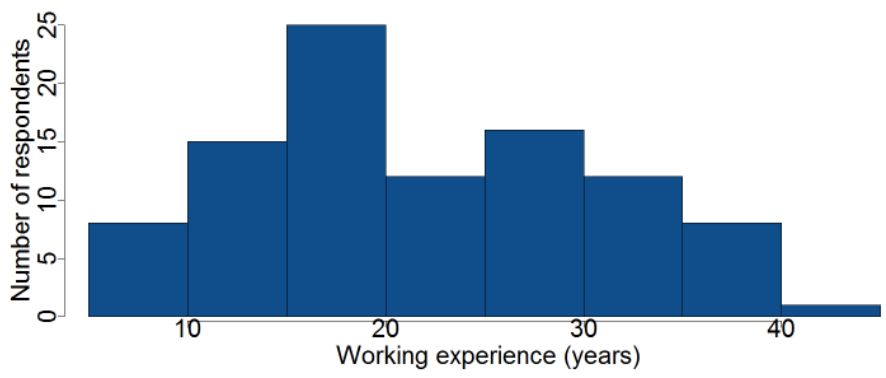

Figure 4 - Distribution of seagoing experience (in years) of Master (M) category of respondents

Years of service range from 9 to 41 , with the mean value of 23.2, standard deviation of 9.1 and the median value amounting to 21 . Respondents were generally classified according to years of their experience in the following categories: $\boldsymbol{A}(0-10)$; $\boldsymbol{B}$ (11 - 15); $\boldsymbol{C}$ (16-20); D (21-25); $\boldsymbol{E}$ (26-30); $\boldsymbol{F}$ (31-35); $\boldsymbol{G}$ (36-41) and $\boldsymbol{H}$ (undefined).

The respondents were further categorized according to their experience with the system, as shown in Figure 5. The categories were defined as $\boldsymbol{a}$-Never had the opportunity to operate with the ECDIS system; $\boldsymbol{b}$ - Less than 6 months; $\boldsymbol{c}$ - Between 6 months and one year; $\boldsymbol{d}$-Between one and two years; $\boldsymbol{e}$ - Between two and three years; $\boldsymbol{f}$ - Between three and four years; $\boldsymbol{g}$ - Between four and five years; $\boldsymbol{h}$ - more than five years and $\boldsymbol{i}$ - other (more than 10 years of ECDIS experience).

\begin{tabular}{|l|l|}
\hline Cat & No. \\
\hline a & 13 \\
\hline b & 10 \\
\hline c & 6 \\
\hline d & 5 \\
\hline e & 7 \\
\hline f & 5 \\
\hline g & 13 \\
\hline h & 33 \\
\hline i & 7 \\
\hline
\end{tabular}

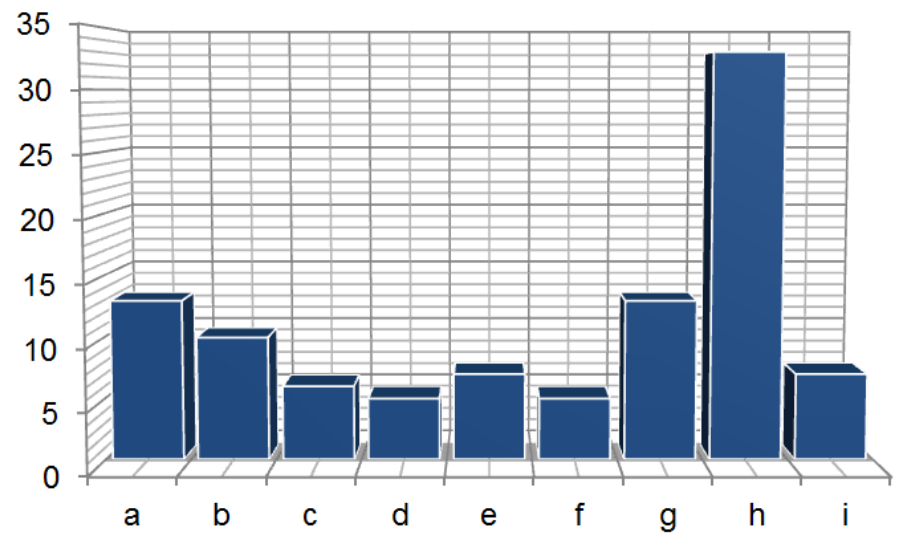

Figure 5 - Share of Masters by their ECDIS experience

After the described categorizations of Masters, the obtained answers and comments were analyzed and discussed as shown in sections that follow. 


\section{Results}

The general share of answers on $Q 1$ is shown in Figure 6. Most of respondents do not agree with the paper chart withdrawal, although the share is close to one half. The NA answer (blank column or ambiguous answer) was present in few cases, making a $3 \%$ share of total responses.

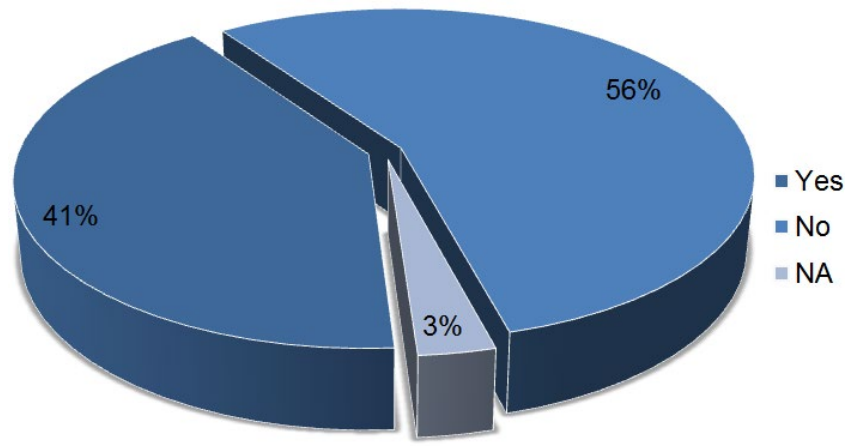

Figure 6-General share of answers regarding agreement with paper chart withdrawal (Q1)

The answers were further elaborated regarding the seagoing experience (Figure 7) and the experience with the system (Figure 8). The share of answers is presented in percentages of the relative sample: the number of respondents for each defined category equals to $100 \%$, with the share of three possible answers (Yes/No/NA) distributed within the bars.

\begin{tabular}{|l|r|r|r|}
\hline Cat & Yes & No & NA \\
\hline A & 5 & 3 & 0 \\
\hline B & 4 & 10 & 0 \\
\hline C & 13 & 13 & 0 \\
\hline D & 6 & 6 & 0 \\
\hline E & 7 & 7 & 2 \\
\hline F & 4 & 8 & 0 \\
\hline G & 1 & 7 & 1 \\
\hline H & 2 & 0 & 0 \\
\hline
\end{tabular}

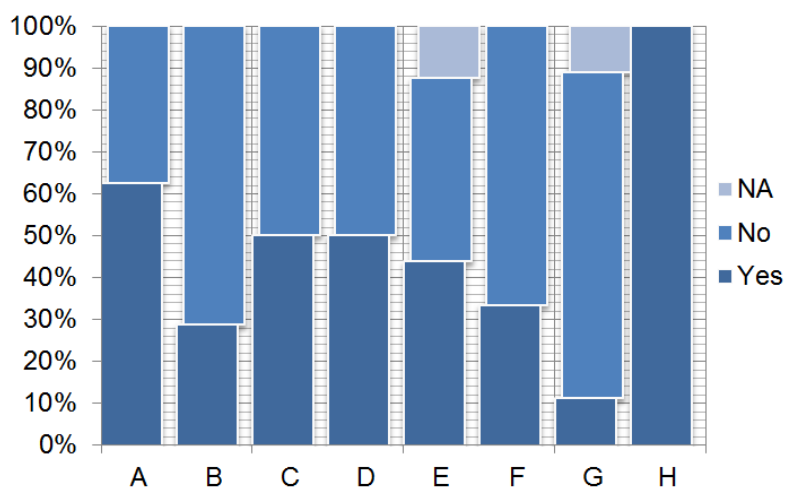

Figure 7 -Master's share of answers on agreement with paper chart withdrawal (Q1: seagoing experience categories

Considering Yes/No answers it can be seen that, as the seagoing experience increases (Figure 6), the agreement with paper charts withdrawal roughly decreases, 
with the strongest disagreement present in the category of Masters with the longest sea experience (categories $\boldsymbol{F}$ and $\boldsymbol{G}$ ). This was somehow expected, given that these seafarers have used paper charts and traditional navigation means for the major portion of their years of service. However, except for categories $\boldsymbol{A}$ (0-10 years) and $\boldsymbol{H}$ (undefined experience), the share of answers goes in favor of paper charts' retention.

\begin{tabular}{|l|r|r|r|}
\hline Cat & Yes & No & NA \\
\hline $\mathrm{a}$ & 4 & 9 & 0 \\
\hline $\mathrm{b}$ & 4 & 5 & 1 \\
\hline $\mathrm{c}$ & 1 & 4 & 1 \\
\hline $\mathrm{d}$ & 3 & 2 & 0 \\
\hline $\mathrm{e}$ & 3 & 4 & 0 \\
\hline $\mathrm{f}$ & 3 & 2 & 0 \\
\hline $\mathrm{g}$ & 6 & 6 & 1 \\
\hline $\mathrm{h}$ & 15 & 17 & 1 \\
\hline $\mathrm{i}$ & 3 & 4 & 0 \\
\hline
\end{tabular}

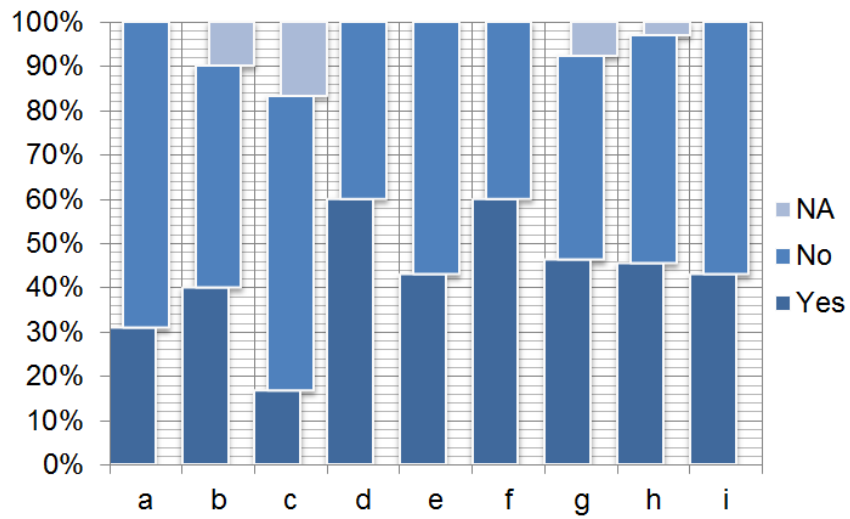

Figure 8-Master's share of answers on agreement with paper chart withdrawal (Q1): ECDIS experience categories

As for the ECDIS experience (Figure 8), the share of answers by the category does not follow a regular trend. Disagreement with paper chart withdrawal prevails in each case except for $\boldsymbol{d}$ (1-2 years) and $\boldsymbol{f}$ (3-4 years) category, being also present in categories of most experienced Masters (categories $\boldsymbol{h}$ and $\boldsymbol{i}$ ). Again, the expected share regarding paper chart retention is obvious within the group of Masters who have never had the opportunity to work with the system (category $\boldsymbol{a}$ ). Among all inexperienced users (41 respondents), 13 of them were Masters (Figure 9).

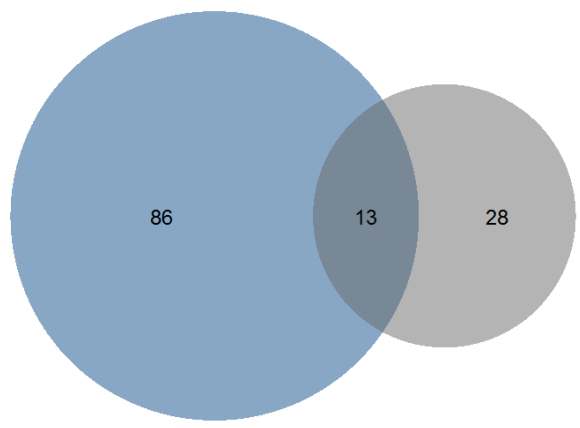

Figure 9 - Venn diagram showing Masters (left circle), ECDIS inexperienced users (right circle) and share of inexperienced users in Masters' category of respondents 
The share of $Q 1$ answers of inexperienced Masters is shown in Figure 10 with the categorization of respondents according to their years of seagoing experience. Considering opinions of inexperienced Masters, it can be seen that their disagreement with paper chart withdrawal is mainly prevailing, notwithstanding the small sample of this specific category.

\begin{tabular}{|l|r|r|}
\hline Cat & Yes & No \\
\hline A & 0 & 2 \\
\hline B & 0 & 0 \\
\hline C & 1 & 0 \\
\hline D & 1 & 1 \\
\hline E & 1 & 3 \\
\hline F & 0 & 2 \\
\hline G & 0 & 1 \\
\hline H & 1 & 0 \\
\hline
\end{tabular}

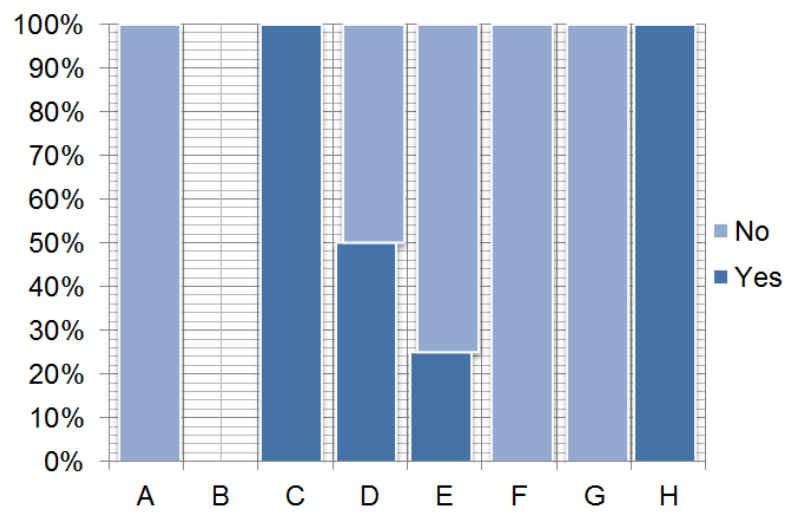

Figure 10 - Inexperienced Masters: share in answers on agreement with paper chart withdrawal (Q1)

It is quite unlikely that there are ECDIS inexperienced OOWs still today. However, the share of answers in this category was somehow expected, given that they have never had the opportunity to work with the system. However, the share of answer is similar compared to the overall Masters' share (Figure 6) with various levels of ECDIS experience: 55 of respondents (56\%) do not agree with the paper chart withdrawal, 41 (41\%) agree, while 3 Masters did not answer the respective question.

Figure 11 shows the general share of answers to $Q 2$. Advantages of the traditional navigation means over the electronic charts and navigation with the ECDIS system are recognized by $62 \%$ of the total number of respondents. The NA answer is here more pronounced than in the previous share.

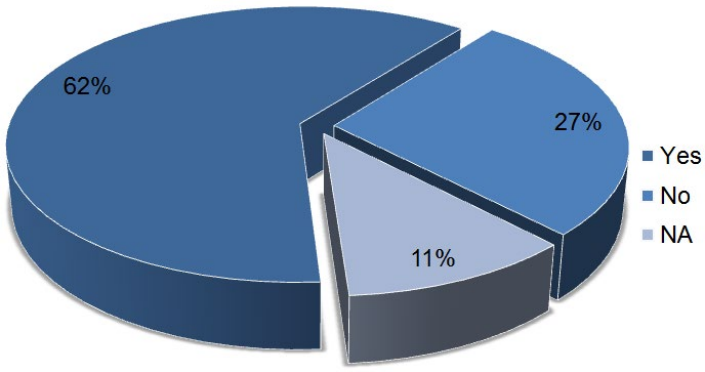

Figure 11 - Share of answers to the question regarding advantages of paper charts and traditional navigation means over ECDIS system and electronic charts (Q2) 
The survey was conducted during 5 years. During this major portion of the transitional period, several changes occurred regarding the system, standards and the ease in system handling and perception (as described in the background chapter). In 2018, up to the completion date, nine Masters among all respondents filled in the questionnaire. Only one respondent stated that there were no advantages of paper charts and traditional navigation means compared to the ECDIS/ENC navigation. All 9 Masters had experience with the system, mainly over five years (category $\boldsymbol{h}$ ). On their vessels, there was at least one official system installed and in all cases ECDIS was approved as the primary navigational means. Furthermore, all except one were in possession of the ECDIS Generic Certificate and at least one familiarization. Be it by chance or not, that respondent was the one whose answer to the respective question was negative.

\section{Discussion}

In general, the system is accepted as a primary navigational means, future navigation tool and technical improvement. Although a certain share of respondents agrees with the paper chart withdrawal, they mostly maintain that a minimum set of paper charts should be kept as a back-up, either as an emergency means (power dependent) or for preferred usage in certain situations, like port approaching and coastal navigation. They favor coastal and small scale paper charts. According to worst case scenarios, paper charts (even outdated) are considered better than the (faulty) ECDIS system. Some of respondents state that despite their paperless status on-board they feel safer with a take-me-home set of paper charts. Figure 12 shows the trend of opinions regarding paper chart withdrawal over the years.

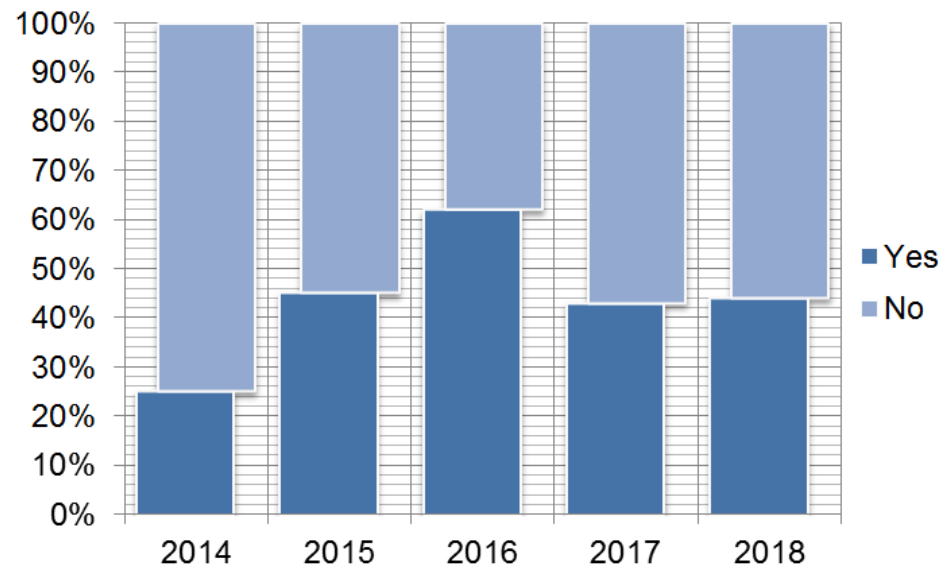

Figure 12 - Trend of opinions regarding paper chart withdrawal agreement (Q1) in the period 2014-2018 
The main reason why paper charts should be kept is the vulnerability of the system, considered as prone to failure and black-out consequences. Unreliability of the system is recognized as a relevant factor but also due to issues regarding electronic charts, ranging from their lack of clarity/readability, cartographic errors, insufficient coverage (including inappropriate ENC scales) and low-grade ENC and updating services. The last two factors are not end-user dependent; they are rather a matter of higher-instance problem solving. The same goes for flag state administrations and regulations which differ between countries, starting from education means onwards. Changes in higher instances are also reflected on end-users' opinions, together with their interpretation and handling.

Readability/legibility acts as the main feature of paper charts advantages over the ECDIS system. This is a concrete end-user issue, resulting from a particular respondent level of familiarization. The majority of respondents still find paper charts and traditional navigation more reliable. In their opinion, the new equipment does not satisfy safety standards for reliable navigation conduct. Several respondents propose certain improvements/additional services, such as chart-on-demand and possibility of printing on board. The same goes for updates, where they propose availability of chart updates by means of satellite communication.

There is no straightforward regularity in answers, i.e. Masters' answers regarding paper chart withdrawal $(Q 1)$ and traditional navigation advantages over the ECDIS system (Q2). Regardless of their (system and seagoing) experience and their generic and type specific education, both possible answers are present in each defined category. For example, the agreement with paper charts withdrawal does not grow with the ECDIS experience (Figure 8). Moreover, advantages of ECDIS over traditional navigation were not recognized over the years of the transitional period (Figure 13). On the contrary, in $2018,89 \%$ of respondents have claimed paper chart advantages as compared with the system. It could be a matter of familiarization, but also a recognition of drawbacks.

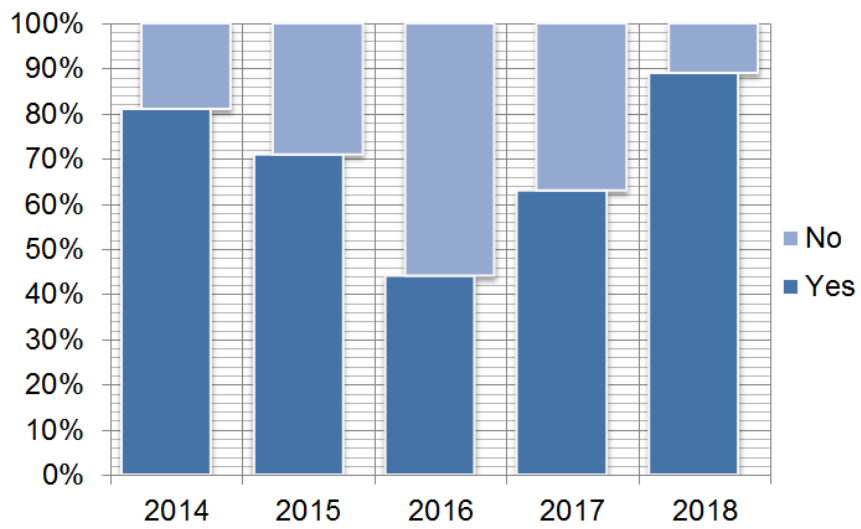

Figure 13 - Trend of opinions regarding advantages over ECDIS system (Q2) in the period 2014-2018 
The problem is how one is used to, and how much time he needs for a certain information to gain. Whether paper or electronic, charts (with accompanying means) represent a navigational aid only. Several key points can be extracted as summarized findings:

- The ECDIS system is accepted as a new primary navigational means, however there are certain issues remaining, differing in their nature; there are several problems which Masters and other officers are pointing to, and they are completely justified;

- The level of technical fulfillment of all ECDIS components still remains incomplete;

- The level of qualification/education is not yet satisfactory;

- For the time being, the official ECDIS and APC on board are the preferred solution among the elaborated group of survey respondents;

- Although already recognized, there appears the problem of over-reliance as seen from the decisive end-user's point of view.

This must be confusing for seafarers to a certain extent. There is the emergence of new technologies with e-Navigation representing one of them, perhaps the most ambitious one. On the other hand, there has been no satisfactory level of understanding and perception of the accepted system - the ECDIS - as yet. Several respondents consider themselves older, justifying in this way their support to traditional navigation. This fact represents a potential problem because considering their responsibilities on board they have to be familiar and versed with the system, regardless of their opinion. The question which arises is how much they really get in contact with the system. There should be no place for intentional ignorance. The differing role of a navigational rank requires a certain level of interpretation, skills and knowledge. Therefore, the emphasis should be put on the particular OOW involvement and a proper approach.

\section{Conclusions and future tendencies}

Since 2018 onwards, an ECDIS system is mandatory on board all respective vessels subject to the SOLAS Convention. Moreover, in case certain requirements are satisfied, the obligation to possess APC ceases. In this case, OOWs are relying on electronic means only, unless the ESP is required. The ECDIS system is recognized as a means of navigation safety improvement. The vision of navigation with ECDIS keeps up with new technologies, such as integrated navigation systems, cloud-based technologies and e-Navigation. The survey-based study presented in this paper focused on opinions of end-users regarding the system and its role as a replacement for traditional navigational means. Among all respondents, the category of Masters as decisive and responsible end-users was elaborated. Answers and opinions were analyzed as collected over the years of the transitional period. The research results opened several questions regarding involvement of particular rank on board vessels with the system. There is 
no straightforward proof of ECDIS acceptance either with the increase of experience with the system or regarding several levels of education. Advantages of traditional navigational means over the ECDIS system are highly represented, as derived from respondents' comments and discussions. As the most responsible subjects on board, Masters simply have to be versed in the system, notwithstanding their involvement in the navigation conduct, as well as their certain attitudes. This is often not the case, and it represents a potential safety threat. At the very current stage, it has become intolerable.

Improvements of educational processes are essential in order to gain a clean, undisturbed interaction among ECDIS stakeholders, especially among OOWs. Improvements are reflected in further activities that will take place in the time to come. One of the proposals is certainly the development of new courses customized to a particular rank, according to their role in the system handling. It especially refers to Masters, where the system should be interpreted on a management level. It is obvious that future officers, eventually Masters will have a direct contact with the system, since for the time being it represents mandatory navigational equipment. However, a significant and responsible task is EET, which should also develop in pace with the system evolvement.

\section{Acknowledgements}

This study has been financially supported by the University of Rijeka under the Faculty of Maritime Studies projects. Authors are grateful to all the officers of the navigational watch for their time and willingness for the fulfillment of the survey, discussions and their opinions. Authors believe that their answers have an immense significance for the appropriateness of the research deliverables.

\section{References}

1. Becker-Heins, R. (2014) ECDIS Basics. Lemmer: Geomares BV.

2. Brčić, D., Kos, S. \& Žuškin, S. (2015) Navigation with ECDIS: Choosing the proper secondary positioning source. TransNav: International Journal on Marine Navigation and Safety of Sea Transportation. 9(3), 317-326.

3. Brčić, D., Kos, S. \& Žuškin, S. (2015) Partial structural analysis of the ECDIS EHO research: The handling part. In: Rijavec, R. (ed.) Proceedings of the 24th International Symposium on Electronics in Transport (ISEP24). Ljubljana: Electrotechnical Association of Slovenia \& ITS Slovenia, 2016, pp. 80-87.

4. Brčić, D., Žuškin, S. \& Barić M. (2017) Observations on ECDIS Education and Training. In: Weintrit, A. (ed.) Proceedings of 12th International Conference on Marine Navigation and Safety of Sea Transportation (TransNav 17). Gdynia, Poland, 21-23.06.2017. London: CRC Press, 2017. pp. 29-36.

5. Brčić, D., Žuškin, S., Valčić, S. \& Frančić, V. (2018) Implementation of the ECDIS system: An OOW perspective as an integral part of educational improvement. In: Grifoll, M. et al. (eds.) Proceedings of 19th IAMU AGA Conference (IAMU 19). Barcelona, Spain, 17-19.10.2018. Barcelona: Universitat Politecnica de Catalunia/International Center for Numerical Methods in Engineering. pp. 121-128. 
6. Danish Maritime Accident Investigation Board (DMAIB) (2015). Available from: http://www. dmaib.com/Sider/Home.aspx [Accessed October 3rd, 2018]

7. Federal Bureau of Maritime Casualty Investigation (BSU) (2018). Available from: http://www. bsu-bund.de/EN [Accessed October 3rd, 2018]

8. French Marine Accident Investigation Office (BEAmer) (2018). Available from: http://www. beamer-france.org/index-en.html [Accessed October 3rd, 2018]

9. Grant, S.T. \& Goodyear, J. (2004) ECDIS: Past, Present and Future. Intergovernmental Oceanographic Commission. Available from: http://www.unesco.org/new/en/natural-sciences/ ioc-oceans/ [Accessed September 21st, 2018]

10. Hamilton, A. C. \& Nickerson, B. G. (1982) The Electronic Chart. Fredericton: University of New Brunswick. Department of Geodesy and Geomatics Engineering.

11. International Electrotechnical Commission (IEC) (2014). IEC 62288: Presentation of navigationrelated information on shipborne navigational displays - General requirements, methods of testing and required test results, Edition 2.0. Geneve: IEC.

12. International Electrotechnical Commission (IEC) (2015). IEC 61174: Electronic chart display and information system (ECDIS) - Operational and performance requirements, methods of testing and required test results, Edition 4.0. Geneve: IEC.

13. International Hydrographic Organization (IHO) (2014). IHO Report on the results of the ECDIS survey conducted by BIMCO and Denmark. Monaco: IHO.

14. International Hydrographic Organization (IHO) (2014). S-52: Presentation Library, Annex A, Edition 4.0. Monaco: IHO.

15. International Hydrographic Organization (IHO) (2014). S-52: Specifications for Chart Content and Display Aspects of ECDIS, Edition 6.1. Monaco: IHO.

16. International Hydrographic Organization (IHO) (2015). S-63: Data Protection Scheme, Edition 1.2. Monaco: IHO.

17. International Hydrographic Organization (IHO) (2017). Information on IHO Standards related to ENC and ECDIS. Version 1.1. Monaco: IHO.

18. International Hydrographic Organization (IHO) (2017). S-64: Test Data Sets for ECDIS, Edition 3.0. Monaco: IHO.

19. International Hydrographic Organization (IHO) (2018). Current IHO ECDIS and ENC Standards. Available from: http://bit.ly/2pjmCyW [Accessed May 1st, 2018]

20. International Maritime Organization (IMO) (1995). A.817(19): Performance standards for Electronic Chart Display and Information Systems (ECDIS). London: IMO.

21. International Maritime Organization (IMO) (1996). MSC.64(67): Adoption of new and amended performance standards. London: IMO.

22. International Maritime Organization (IMO) (1998). MSC.86(70): New and amended performance standards for navigational equipment. London: IMO.

23. International Maritime Organization (IMO) (2006). MSC.232(82): Adoption of the revised performance standards for Electronic Chart Display and Information Systems (ECDIS). London: IMO.

24. International Maritime Organization (IMO) (2009). NCSR 2/22/2: Report on monitoring of ECDIS issues by IHO. London: IMO, 2009.

25. International Maritime Organization (IMO) (2010). MSC.1/Circ. 1391: Operating anomalies identified within ECDIS. London: IMO.

26. International Maritime Organization (IMO) (2012). Model Course 1.27: Operational use of Electronic Chart Display and Information System. London: IMO.

27. International Maritime Organization (IMO) (2013). NAV 59/12/1: Report on monitoring of ECDIS issues by IHO. London: IMO.

28. International Maritime Organization (IMO) (2014). International Convention for the Safety of Life at Sea, 1974 as amended. London: IMO.

29. International Maritime Organization (IMO) (2017). MSC.1/Circ.1503 Rev.1: ECDIS - Guidance for good practice. London: IMO.

30. Kerr, A. (1990) Status report on activities of IMO and IHO concerning the electronic chart. International Hydrographic Review. 7-16.

31. Marine Accident Investigation Branch (MAIB) (2018). Available from: https://www.gov.uk/ government/organisations/marine-accident-investigation-branch [Accessed October 1st, 2018] 
32. Overgard, K. I. \& Smit, P. N. (2014) Effect of sea experience and computer confidence in ECDIS training. In: Martinez de Oses, F. X. \& Castells Sanabra, M. (eds.) Proceedings of 6th International Conference on Maritime Transport (MT14). Barcelona, Spain, 25-27.2014. Barcelona: UPC. pp. 297-310.

33. Powell, J. (2011) the New Electronic Chart Product Specification S-101: An Overview. In: Weintrit, A. (ed.) International recent issues about ECDIS, E-navigation and safety at sea. Boca Raton: Taylor \& Francis Group Ltd. pp. 69-73.

34. The Nautical Institute (NI) (2015). Navigation Accidents and their Causes. London: The Nautical Institute.

35. United Kingdom Hydrographic Office (UKHO) (2016). Majority of global SOLAS fleet now ECDIS ready. Press release. London: UKHO.

36. Weintrit, A. (2011) International recent issues about ECDIS, E-navigation and safety at sea: Introduction. In: Weintrit, A. (ed.) International recent issues about ECDIS, E-navigation and safety at sea. Boca Raton: Taylor \& Francis Group Ltd. pp. 9-12.

37. Weintrit, A. (2015) ECDIS issues related to the implementation of the carriage requirements in SOLAS Convention. Archives of Transport System Telematics. 8(1), 35-40.

38. Žuškin, S., Brčić, D. \& Kos, S. (2016) Partial structural analysis of the ECDIS EHO research: The safety contour. In: Martinez de Oses, F. X. \& Castells Sanabra, M. (eds.) Proceedings of 7th International Conference on Maritime Transport (MT16). Barcelona, Spain, 27-29.06.2016. Barcelona: UPC. pp. 246-262.

39. Žuškin, S., Brčić, D. \& Šabalja, Đ. (2013) A contribution to improving the standards of ECDIS training. Pomorstvo - Scientific Journal of Maritime Research. 27(1), 131-148. 
